\title{
Nonregenerative Axonal Growth Within the Mature Mammalian Brain: Ultrastructural Identification of Sympathohippocampal Sprouts
}

\author{
Keith A. Crutcher ${ }^{1, a}$ and Carl F. Marfurt ${ }^{2}$ \\ 'Department of Anatomy, University of Utah School of Medicine, Salt Lake City, Utah, and 2Department of Anatomy, \\ Northwest Center for Medical Education, Indiana University School of Medicine, Gary, Indiana
}

Damage to septohippocampal neurons in the adult rat results in sprouting of sympathetic axons into the denervated hippocampal formation. However, the distribution of sympathohippocampal fibers has only been assessed with light microscopic techniques, and it is not known if the sprouted fibers leave the blood vessels, along which they migrate into the hippocampal formation, to enter the hippocampal neuropil and, if they do, whether they form synaptic contacts with central neurons. Using the tetramethylbenzidine technique to visualize anterogradely transported wheat germ agglutinin-horseradish peroxidase conjugate, we identified sprouted sympathetic fibers in the hippocampal formation at both the light and electron microscopic level in albino rats receiving medial septal lesions. The majority of labeled fibers were observed within the regions immediately above and below the granule cell layer. Although most of the labeled sprouts were observed in association with intraparenchymal blood vessels, where they were usually apposed to the basal lamina, approximately a third of the labeled profiles were present within the neuropil with no obvious vascular relationships. Most of the profiles were identified as unmyelinated axons or vesicle-filled varicosities. Many of the latter structures contained small dense-cored vesicles, but in our sample none of the labeled profiles were observed to form membrane specializations with adjacent structures, and many were partly surrounded by presumed astrocytic processes. These results document the invasion of the CNS by sprouting axons of peripheral origin indicating that axonal elongation from uninjured neurons can occur within the mature mammalian CNS under certain circumstances. In addition, the presence of significant numbers of sympathetic fibers within the hippocampal neuropil indicates that they may be in a strategic position to influence hippocampal function.

Although the developing CNS is characterized by extensive axonal growth and synaptogenesis, axonal elongation (regeneration and sprouling) in the mature organism is usually restricted

\footnotetext{
Received Apr. 27, 1987; revised Sept. 4, 1987; accepted Nov. 6, 1987.

This work was supported by NIH Grant NS-17131 and NSF Grant BNS-8501269 (K.A.C.), and DE07133 and EY05717 (C.M.). We wish to thank Yvonne Mueller, Lilian Gerity, Diane Zarate, Deborah Huseman, and Cynthia Welther for their excellent technical assistance. The secretarial assistance of Nancy Peixhot, Karen Evans, and Connie Gelber is also appreciated.

Correspondence should be addressed to K. A. Crutcher at the address below.

a Present address: Department of Neurosurgery, University of Cincinnati Medical Center, 231 Bethesda Avenue, Cincinnati, Ohio 45267-0515.

Copyright (C) 1988 Society for Neuroscience $0270-6474 / 88 / 072289-14 \$ 02.00 / 0$
}

to the PNS of mammals or to the CNS of some nonmammalian vertebrates (Ramon y Cajal, 1928; Windle, 1956; Guth, 1974; Kiernan, 1979). The failure of axons to elongate within the mature CNS was recognized in the 19th century and documented extensively by Ramon y Cajal (1928) and others in the early part of this century. Cajal concluded-based on the experimental results of Tello (1911), Lorente de No (1921), and others - that axonal growth within the mature mammalian CNS was abortive due to the absence of "tropic substances" which continue to be produced in the PNS, presumably by Schwann cells. Another possibility, however, is that neurons intrinsic to the mammalian CNS lose their ability to extend axons as a normal consequence of maturation (Clark, 1942, 1943). Definitive experimental data needed to distinguish between these 2 hypotheses were not available until recently.

Aguayo and coworkers (Richardson et al., 1980; David and Aguayo, 1981; Aguayo et al., 1982, 1986; Benfey and Aguayo, 1982) examined the regenerative potential of CNS neurons in the rat with contemporary hodological and grafting techniques. In a thorough series of experiments, the ability of central neurons to undergo extensive axonal elongation was assessed by inserting a segment of peripheral nerve into various regions of the CNS and retrogradely labeling regenerating neurons by injecting tracer substances into the nerve graft. The definitive conclusion that can be drawn from these experiments is that neurons normally confined to the CNS will support axonal elongation if provided with the appropriate "environment," i.e., peripheral nerve tissue, thereby supporting Cajal's conclusions. These results were obtained from studies of regenerating axons, the growth occurring from injured neurons (Aguayo, 1985). Whether uninjured central ncurons will clongate axons within similar grafts has been more difficult to determine since most studies necessarily involve injury to the responsive neurons.

Although the dogma that central neurons cannot extend axons within the mature CNS is widely accepted, there are some suggestions that central axonal regeneration can occur. For example, apparent regrowth of some central noradrenergic and serotonergic axons occurs following neurotoxic lesions (Nygren et al., 1971, 1974; Nobin et al., 1973). Injection of NGF (Bjorklund and Stenevi, 1972) or the implantation of various tissues has also been reported to promote regeneration (Emson et al., 1977; Bjorklund and Stenevi, 1979, 1984; Kromer et al., 1981). However, the most documented form of neuronal plasticity in the mature brain and spinal cord is nonregenerative axonal growth (collateral sprouting), i.e., a response on the part of uninjured neurons to loss of other inputs in a target field. One distinction between regenerative and nonregenerative axonal growth is that the latter, by definition, is initiated by changes within the axonal 
environment and is not the result of direct injury to the responsive neuron. Although collateral sprouting could involve axonal growth, most occurrences are thought to represent examples of "reactive synaplogenesis" or terminal sprouting (Liu and Chambers, 1958; Raisman, 1969; Cotman et al., 1973; Raisman and Field, 1973; Gage et al., 1984), which does not necessarily require significant axonal elongation (Cotman and Nieto-Sampedro, 1981). Other examples of neuronal plasticity, particularly during development, may represent the retention of a normally transient projection or expansion of a previous innervation, again, not requiring new axonal growth (Schneider, 1973).

One example of collateral sprouting that docs appcar to involve significant axonal growth is the invasion of the hippocampal formation by sympathetic axons following septohippocampal denervation (Stenevi and Bjorklund, 1978; Loy et al., 1980; Crutcher et al., 1981). This phenomenon has been reviewed recently in detail (Crutcher, 1987), so only a few of the most relevant features will be enumerated here. That this particular sprouting response occurs only in response to septal denervation is now fairly certain. In addition, such growth represents collateral sprouting and not a regenerative response since injury to the sympathetic neurons is not required. Of particular interest, regarding the question of axonal elongation, is the fact that sympathetic axons grow from the extracerebral vasculature into the CNS in the absence of any direct injury to the hippocampal tissue or the vasculature. As a result, no glial scar is formed in the area of growth nor is there any indication of a change in the density of blood vessels (Chandler and Crutcher, 1983).

Previous work has shown that the sprouted sympathohippocampal axons are at least partly associated with intraparenchymal blood vessels inside the dentate gyrus and CA3 region of the hippocampus (Stenevi and Bjorklund, 1978; Loy and Moore, 1979; Crutcher et al., 1981; McGinty et al., 1982; Crutcher and Chandler, 1984). In fact, the sprouted fibers were identified at the electron microscopic level in a previous study as a result of their separation from both the blood vessel and the adjacent neuropil by conspicuous basal laminae (Crutcher and Chandler, 1984). However, whether the sympathetic fibers actually entered the neuropil could not be ascertained with routine electron microscopy. The aim of the present study was to determine whether the vascular association of sympathetic sprouts is absolute and, if not, to determine to what extent the sympathetic fibers actually enter the hippocampal neuropil and engage in synaptic relationships with intrinsic neurons. In order to obtain unequivocal identification of sympathohippocampal fibers at the electron microscopic level, we have labeled them with wheat germ agglutinin-horseradish peroxidase conjugate (WGA-HRP) transported anterogradely from the superior cervical ganglion.

\section{Materials and Methods}

Animals. Female Sprague-Dawley rats were used for this study. A total of 20 animals with satisfactory septal lesions and WGA-HRP injections into the superior cervical ganglion (SCG) provided relevant data, but 3 animals were extensively studied at the ultrastructural level. All animals were housed in the vivarium and treated in accordance with animal care guidelines provided by the NIH.

Lesions. All animals were anesthetized with ketamine and/or Nembutal. Medial septal lesions were made by passing $3 \mathrm{~mA}$ of direct current for $20 \mathrm{sec}$ through an electrode positioned stereotaxically within the septum (bregma used for X and AP coordinates, $\mathrm{Y}$ at $4.9 \mathrm{~mm}$ above the interaural zero, nosebar at $-2.5 \mathrm{~mm}$ ). Control lesions involved use of the same parameters except the electrode was positioned dorsal to the medial septum ( $Y=7.9 \mathrm{~mm}$ above interaural zero). Occasional bleeding from the superior sagittal sinus was controlled with gelfoam and/or bone wax.

Injection procedure and tissue preparation. Six to 12 weeks after placement of the lesion, each animal was reanesthetized and the SCG exposed bilaterally by a ventral midline incision and gentle lateral retraction of the carotid sheaths. Each ganglion was then impalcd with a glass micropipette (tip diameter, 30-40 $\mu \mathrm{m}$ ) connected by a short length of polyethylene tubing to a $10 \mu \mathrm{l}$ Hamilton microsyringe mounted on a microinfusion pump. Stability during the injection procedure was maintained by attaching the micropipette to the microadvance system of a Kopf small animal stereotaxic apparatus. In this fashion, the rigidly mounted pipette tip was lowered under direct visual observation, using a dissecting microscope at $40 \times$ magnification, until penetration of the ganglion was made. Small volumes $(0.4-0.6 \mu 1)$ of $2 \%$ WGA-HRP in saline were then injected slowly into both the rostral and caudal poles of the ganglion. The incision was then closed with cutaneous sutures and the animal returned to its cage. In some animals, efforts were made to maximize tracer uptake by repeating the injection procedure the next day. An additional group of animals served as controls and received SCG injections of WGA-HRP without prior septal or control lesions.

Forty-eight to $72 \mathrm{hr}$ after the initial WGA-HRP injection, the animals were perfused through the ascending aorta with $150 \mathrm{ml}$ of warm, buffered saline containing $0.003 \%$ heparin and $3 \%$ procaine $\mathrm{HCl}$, followed by $500 \mathrm{ml}$ of $1 \%$ paraformaldehyde- $2.5 \%$ glutaraldehyde in $0.1 \mathrm{M}$ cacodylate buffer with $0.012 \% \mathrm{CaCl}_{2}$ for $15-30 \mathrm{~min}$. Fixation was then terminated by perfusing the animal with $500 \mathrm{ml}$ of ice-cold $0.1 \mathrm{M} \mathrm{cac}$ odylate buffer.

Immediately following cessation of the perfusion, the irides and the pineal gland were removed, sectioned, and processed for the presence of HRP activity according to the tetramethylbenzidine (TMB) technique of Mesulam (1978), and examined under dark-field optics with a light microscope. If the irides and pineal gland contained dense plexuses of labeled sympathetic fibers (Marfurt et al., 1986), then the SCG injections were deemed successful and the hippocampal formations removed for subsequent processing.

Serial sections of the hippocampal formation were cut at $40 \mu \mathrm{m}$, in either the coronal or horizontal axis, on a Lancer vibratome. Sections destined for light microscopic analyses were incubated immediately in a standard TMB medium at $\mathrm{pH} 3.7$, mounted on chrome-alum-coated slides, coverslipped, and examined under dark-field optics for the presence of HRP-labeled fibers. The distribution of labeled sympathohippocampal fibers was plotted onto line drawings using a drawing tube attachment mounted on an Olympus BH2 light microscope. Representative sections were photographed using a dark-field condenser with polarizing filters.

Sections destined for electron microscopic analyses were incubated in a TMB medium at a more neutral $\mathrm{pH}(6.0)$. This procedure decreased

\footnotetext{
Figure 1. Line drawings of horizontal $(A)$ and coronal $(B)$ sections through the hippocampal formation illustrating the distribution of HRP-labeled sympathohippocampal fibers approximately 2 months following a medial septal lesion. The drawings were made from $40-\mu \mathrm{m}$-thick frozen sections. An area similar to the boxed area in $B$ is illustrated at higher magnification in $C . F$, fimbria; $D$, dentate gyrus; $C A 1$, CAl region of hippocampus; $C A 3$, CA3 region of the hippocampus. $C$, Line drawing of a $1-\mu \mathrm{m}$-thick plastic section, showing the distribution of HRP-labeled fibers in the medial portion of the dentate gyrus. The open circles and oval-shaped profiles are blood vessels, and the solid black dots are HRP-labeled fibers. Examples of labeled profiles associated with vascular elements are indicated by arrows, whereas examples of labeled profiles with no obvious vascular
} 


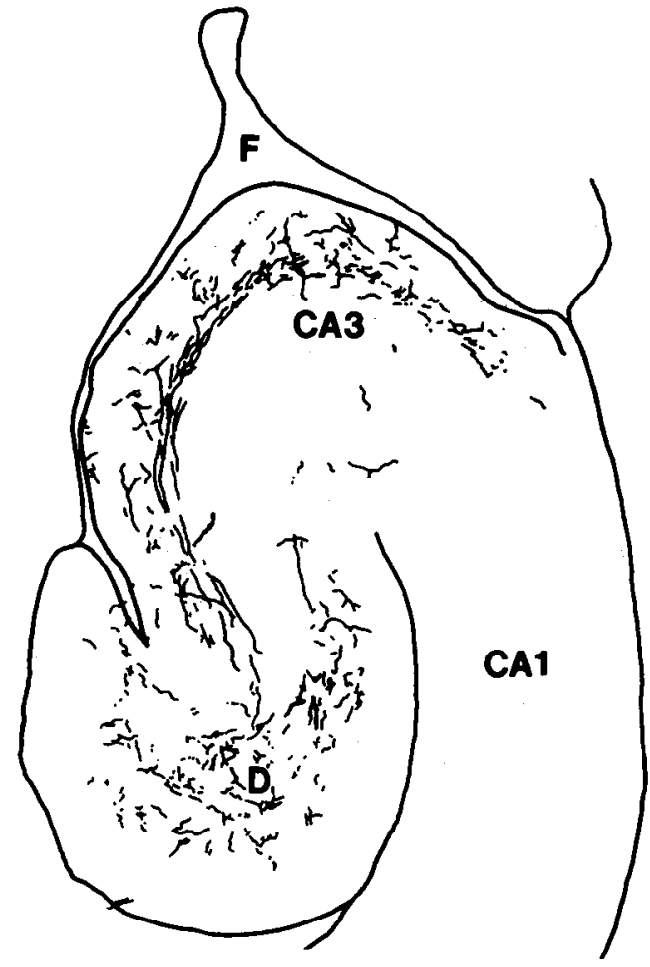

A



$\mathbf{B}$

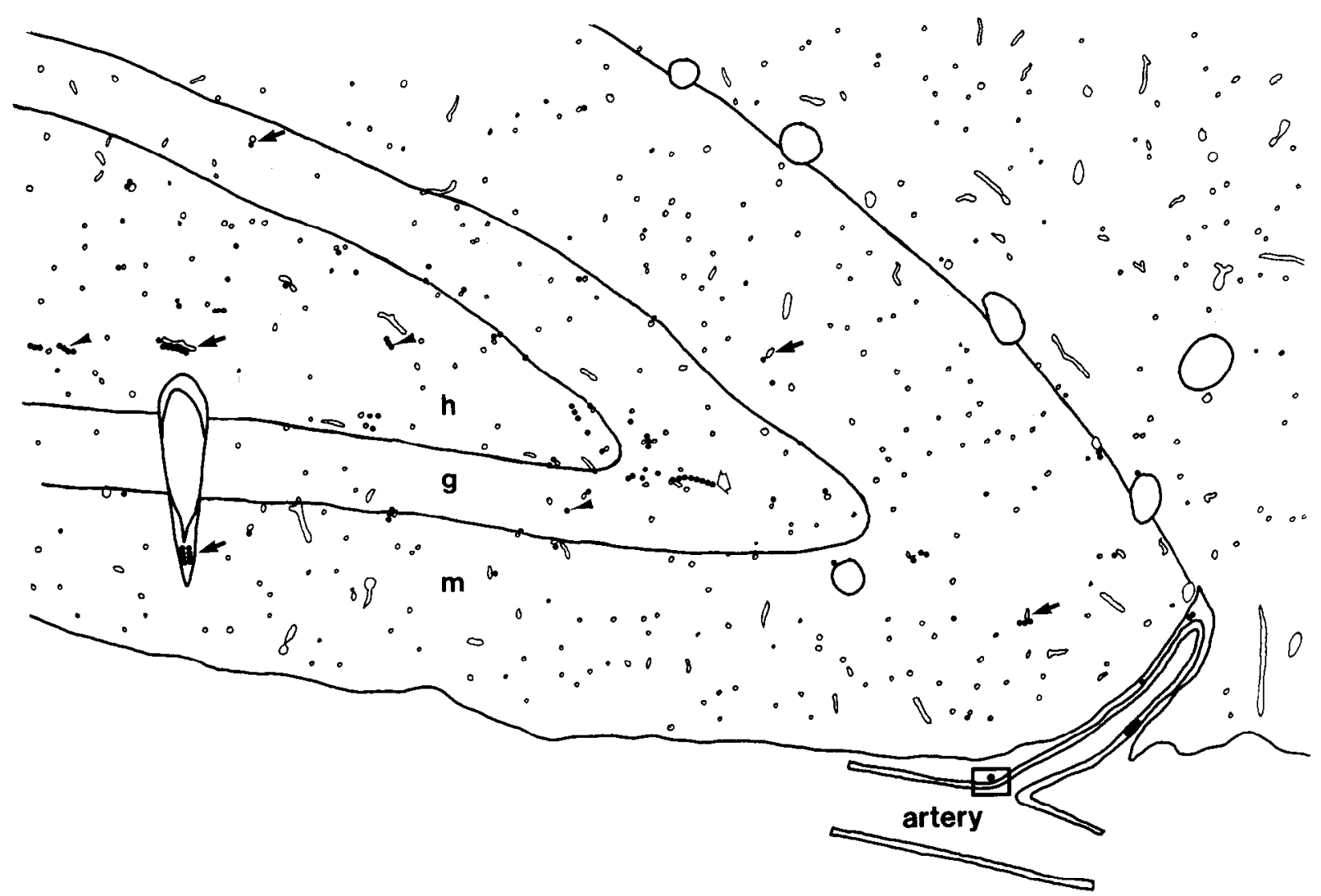

C

association are indicated by arrowheads. The single open arrowhead near the center of the figure points to a clear example of a labeled fiber leaving its association with a blood vessel to enter the hippocampal neuropil. In the area illustrated, 22 of 60 labeled fibers (37\%) were located in the hippocampal neuropil, and all of these were present in the granular layer and hilus. The boxed area at the lower right of the micrograph illustrates the location of the labeled myelinated nerve fiber illustrated in Figure $3 A$. $h$, hilus; $g$, granule cell layer; $m$, molecular layer of dentate. 

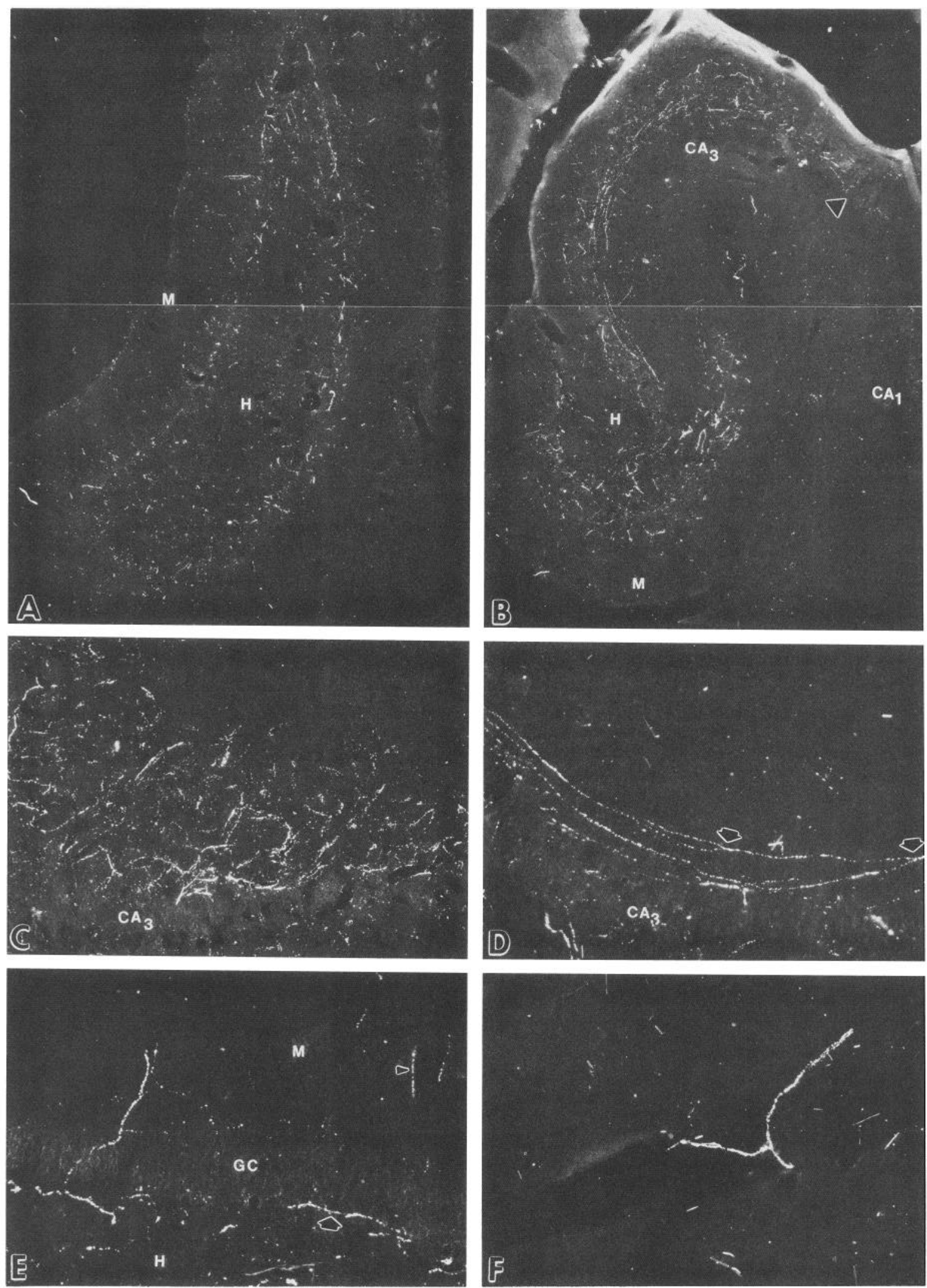

Figure 2. Dark-field micrographs of HRP-labeled sympathetic fibers in the hippocampal formation following septal lesions in the rat. A, Montage of a coronal section through the posterior hippocampal formation illustrating the distribution of HRP-labeled fibers within the dentate gyrus. The plane of section reveals a perimeter of granule cells separating the hilus $(H)$ and molecular layer $(M)$. The hippocampal fissure is at the far righthand side of the field. The sympathetic fibers cluster above and below the granule cell layer. $B$, Horizontal section through the ventral hippocampal formation to illustrate the restriction of sympathetic fibers to the dentate gyrus and CA3 region of the hippocampus. The arrowhead indicates the transition zone between CA3 and CA1. The lighter portion of the micrograph at the top is the fimbria and alveus. $C$, Dense labeling of sympathetic 
slightly the amount of reaction product that was seen within the sections but provided better ultrastructural preservation of the tissue. Following incubation, the sections were washed briefly in several changes of fresh buffer, then soaked for $15 \mathrm{~min}$ in a solution of $5 \%$ ammonium molybdate in pH 6.0 acetate buffer in order to stabilize and increase the electron density of the TMB crystals (Marfurt et al., 1986). The sections were then rinsed several times in fresh buffer and trimmed into smaller pieces containing the area known on the basis of our light microscopic observations to contain visible reaction product. The sections were then osmicated for 45 min in $1 \%$ osmium tetroxide in 0.1 M cacodylate buffer, $\mathrm{pH} 6.0$, at $45^{\circ} \mathrm{C}$ (Carson and Mesulam, 1982) dehydrated for $7 \mathrm{~min}$ each in a series of graded alcohols and flat-embedded in Spurr's epoxy resin between 2 Teflon-coated coverslips. Following polymerization, the 80 - to 100 -nm-thick resin wafers were glued with quick-setting epoxy to the end of a Spurr's epoxy resin block. Thin sections were viewed in an electron microscope either unstained or poststained lightly with uranyl acetate and lead citrate.

\section{Results}

\section{Control animals}

HRP injections into the SCG of control unlesioned or control lesioned animals resulted, in successful cases, in extensive labeling of sympathetic fibers throughout several structures in the head and neck. In particular, dense plexuses of labeled fibers were observed within the iris where the extent of labeling correlated with similar labeling of structures within the cranial cavity, such as the pineal gland and the large arteries at the base of the brain, as reported by Marfurt and coworkers (1986). The labeled fibers were distributed in the same pattern as observed with the fluorescent histochemical technique of de la Torre (1980), which reveal sympathetic fibers as a result of their norepinephrine content.

Within the region of the hippocampal formation, occasional HRP-labeled fibers were observed in association with the extracerebral longitudinal hippocampal arteries. Such fibers were more abundant at ventral levels of the hippocampal formation, being only rarely observed at dorsal and rostral levels. In none of the control cases (lesioned controls or unlesioned animals) in which extensive labeling of intracranial sympathetic fibers was observed did we find any examples of HRP-labeled fibers within the hippocampal formation.

Examination at the electron microscopic level of tissues from SCG-injected animals that had not received a lesion or had received a lesion that did not interrupt septohippocampal fibers revealed no evidence of TMB-reaction product within the CNS, although reaction product was found in fibers associated with extracerebral blood vessels. Nor was any labeling observed within the hippocampal formation of animals that had not received injections of WGA-HRP in the SCG, although occasional examples of endogenous peroxidase associated with endothelial cells were found.

\section{Septal animals}

\section{Light microscopic observations}

HRP injections into the SCG of animals sustaining lesions of the medial septum resulted in extensive labeling of the same extra- and intracranial sympathetic targets observed in the control animals. In fact, there appeared to be better or more labeling of sympathetic innervations to the cornea and tooth pulp in these same animals (K. A. Crutcher and C. F. Marfurt, unpublished observations). In addition, numerous HRP-labeled fibers were observed al dorsal and ventral levels of the hippocampal formation within the dentate gyrus and CA3 region of the hippocampus.

The distribution of HRP-labeled sprouts within the hippocampal formation is shown in Figures $1, A, B$, and 2 and is reminiscent of the pattern of sympathetic innervation observed with histofluorescent preparations (Crutcher et al., 1981). A drawing illustrating the distribution of labeled fibers within the dorsal hippocampal formation is shown in Figure 1A. Many of the labeled fibers were clearly associated with intraparenchymal blood vessels, but occasional HRP-filled fibers appeared not to have such vascular associations (Figs. $1 C ; 2, C, E$ ).

Labeled fibers entered the dentate molecular layer in association with penetrating blood vessels but were not found to follow the smaller branches coursing at right angles to the parent vessel until reaching the inner third of this layer. At this point, labeled fibers followed vascular branches above, through, and below the granule cell layer. Occasional fibers also followed blood vessels into the dentate hilus, but the majority coursed within the immediate subgranular region. Within the hippocampus proper, HRP-labeled fibers were densely distributed within stratum lucidum of CA 3 and occasionally coursed through the pyramidal layer and into stratum oriens (Fig. 2, C,D). Such fibers did not extend further into stratum radiatum and were not observed within any portion of the CA1 region (Figs. $1 A, 2 B$ ). Although some of the fibers were not associated with any obvious vascular profile, the resolution afforded by the $40-\mu \mathrm{m}$-thick frozen sections was not sufficient to draw definitive conclusions on this point. Examination of $1-\mu \mathrm{m}$-thick plastic sections, however, did provide sufficient resolution to identify reaction product in relationship to the vascular profiles. A line drawing of one such section is shown in Figure $1 C$. In this field, two-thirds of the reaction product was clearly associated with blood vessels, but the remaining third was not.

\section{Electron microscopic observations}

Tissue from the dorsal dentate gyrus was examined at the electron microscopic level from 2 animals in which extensive sympathetic fiber labeling was apparent at the light microscopic level. Thin sections were scanned under low magnification $(\times 4000)$, and then areas containing reaction product, which were clearly visible at this magnification, were examined and photographed at higher magnifications. The reaction product was clearly visible in unstained sections and also in sections stained lightly with lead citrate and/or uranyl acetate. The reaction product varied in size and shape but was typically crystalline in appearance and extremely electron dense. The unique appearance of the reaction product permitted its distinction

\footnotetext{
fibers within the CA3 region of the hippocampus. Most of the labeled fibers are restricted to the zone (stratum lucidum) immediately above the pyramidal cell layer. This zone also corresponds to the dense terminal region of the granule cell axons (mossy fibers). Some, but not all, of the labeled fibers are associated with intraparenchymal blood vessels. $D$, Labeled fibers within the CA3 region that appear to be bifurcating (arrows) and coursing within stratum lucidum in parallel to the pyramidal cell layer $E$, Labeled sympathetic fibers within the dentate gyrus, some of which are associated with blood vessels (small arrowhead), but others of which do not have obvious vascular associations (large arrowhead), $F$, Labeled fiber in association with an extracerebral blood vessel in the vicinity of the hippocampal formation.
} 
from the pigment granules that were present in some of the neurons. The latter were globular in appearance, distinctly mottled, and in every way typical of lipofuscin and neuromelanin pigment as described in other studies. Further confirmation of the ultrastructural appearance of the TMB reaction product was obtained by examining reaction product that had precipitated on the surface of the occasional erythrocyte left in the vasculature. In such cases, TMB crystals extended from the red blood cells for some distance along the lumen of the blood vessel and were easily identified in the electron microscope. Control tissue that had been reacted with TMB failed to reveal any particles that could be construed as reaction product.

Labeled fibers were encountered in association with the longitudinal hippocampal arteries. The majority of these fibers were unmyelinated, but we did encounter one example of a myelinated fiber (Fig. 3A). All of the labeled extracerebral fibers were surrounded by Schwann cells or Schwann cell processes (Fig. $3 B$ ).

Within the outer half of the dentate molecular layer, several penetrating blood vessels had HRP-labeled profiles associated with them (Fig. 3, $C, D$ ), but reaction product was only rarely encountered within the neuropil in this region. The majority of labeled profiles above and below the granule cell layer were also associated with blood vessels (Fig. 4). In order to obtain some indication of the incidence of vascular-associated labeled fibers, photographs were taken of every labeled profile observed in several random sections. In this sample $(n=98), 66 \%$ of the labeled profiles were associated with blood vessels; the remaining third did not exhibit any vascular association. Although the dense reaction product obscured the underlying elements in some cases (Fig. 4, $A, B$ ), in other examples reaction product was clearly visible within several adjacent profiles, indicating that fascicles of labeled sprouts were often present in the perivascular region (Fig. $4, C, D$ ). In most cases, labeled perivascular profiles were in direct contact with the basal lamina surrounding the blood vessel (Fig. 4, $B, D$ ).

Many of the labeled profiles contained vesicles, some of which were of the small dense-cored variety (Fig. 5). These labeled perivascular sprouts usually appeared in direct apposition to the endothelial basal lamina; however, in the sample size afforded by the current investigation $(n=65)$, we did not observe any membrane thickenings. The majority of labeled profiles in the perivascular region were not separated from the neuropil by basal lamina, but many of them were directly apposed to presumed astrocytic processes (Fig. 5C).

Examples of labeled sympathetic sprouts without vascular associations are shown in Figure 6. Many of these labeled sprouts contained vesicles and were found in association with various elements, including astrocytic processes, unmyelinated axons, and other vesicle-containing profiles. However, in none of the 35 labeled profiles, some of which were observed in sequential sections, did we observe membrane specializations. In addition, HRP-labeled axons were found within fascicles, an example of which is shown in Figure $6 F$. These fascicles included up to 25 distinct axons and were usually surrounded, at least in part, by astrocytic processes. The axons within these fascicles ranged in diameter from 0.1 to $1 \mu \mathrm{m}$ and were in direct apposition to each other without intervening glial processes. We did not encounter any labeled myelinated axons in our material except for the one extracerebral profile referred to earlier (Fig. $2 A$ ).

\section{Discussion}

Methodological considerations

The WGA-HRP anterograde transport technique proved to be an excellent method for labeling selectively, at both the light and electron microscopic level, sympathetic nerve fibers that originated from the SCG. At the light microscopic level, when viewed with dark-field optics, labeled fibers appeared as linear arrays of bright, yellow-orange granules that stood out sharply against an otherwise dark gray background. The use of the sensitive TMB chromagen appears to be necessary for the successful visualization of the moderate amounts of WGA-HRP that are transported anterogradely within these fibers. Previous attempts to label these fibers at the light microscopic level using diaminobenzidine (DAB) histochemistry (K. A. Crutcher, unpublished observations) were unsuccessful, and it now appears likely that these negative data were due to the low sensitivity of the $\mathrm{DAB}$ chromagen and the extremely small size of the reaction product granules generated by this procedure. Thus, the WGAHRP tracing technique, combined with the sensitive TMB histochemical procedure, represents a novel method of labeling selectively sympathohippocampal fibers at the light microscopic level. This circumvents the problem of differentiating between central and peripheral noradrenergic fibers on the basis of histochemical fluorescence morphology (Crutcher, 1982) or false transmitter labeling (Loy and Moore, 1979).

At the electron microscopic level, the tracing procedure enabled us to identify unequivocally sympathohippocampal fibers that would have been otherwise indistinguishable, on the basis of normal morphological criteria, from other elements within the surrounding hippocampal neuropil. The labeled fibers were identified readily by the presence of TMB reaction product within their axoplasm. The superior electron density of the TMB granules facilitated greatly their identification even at very low magnifications, and the unique crystalline ultrastructure of the granules made it virtually impossible to mistake them for anything else.

The successful extension of the TMB technique to the electron microscopic level in the current investigation was not accomplished without difficulty. Strict adherence to Carson and $\mathrm{Me}$ sulam's original procedure (1982; see also Sakumoto et al., 1980, and Sturmer et al., 1981), which involves reacting the tissue in TMB at $\mathrm{pH} 3.3$ and osmification at $\mathrm{pH} 6.0$ at $45^{\circ} \mathrm{C}$, resulted, in our hands, in good preservation of TMB crystals but unacceptable loss of ultrastructural detail. Alternatively, we have been able to achieve consistently good results by reacting the tissue in TMB at pH 6.0 in $0.01 \mathrm{M}$ acetate buffer (Schonitzer and Hollander, 1981; Westman et al., 1986), followed by rapid stabilization of the TMB crystals in a $1 \%$ solution of ammonium molybdate (Fujii and Kusama, 1984; Marfurt et al., 1986). The tissue in our study was incubated most often in the TMB medium for approximately $15 \mathrm{~min}$; shorter times led to a significant decrease in the amount of visible reaction product, and longer times resulted in the production of TMB crystals that were so large as to obscure the morphology of the sympathetic sprouts in which they were contained. In fact, even in the best cases, the density of the reaction product obscured some morphological detail. We occasionally encountered examples of TMB crystals that extended for very short distances beyond the membranous confines of the sympathetic axon and into adjacent 

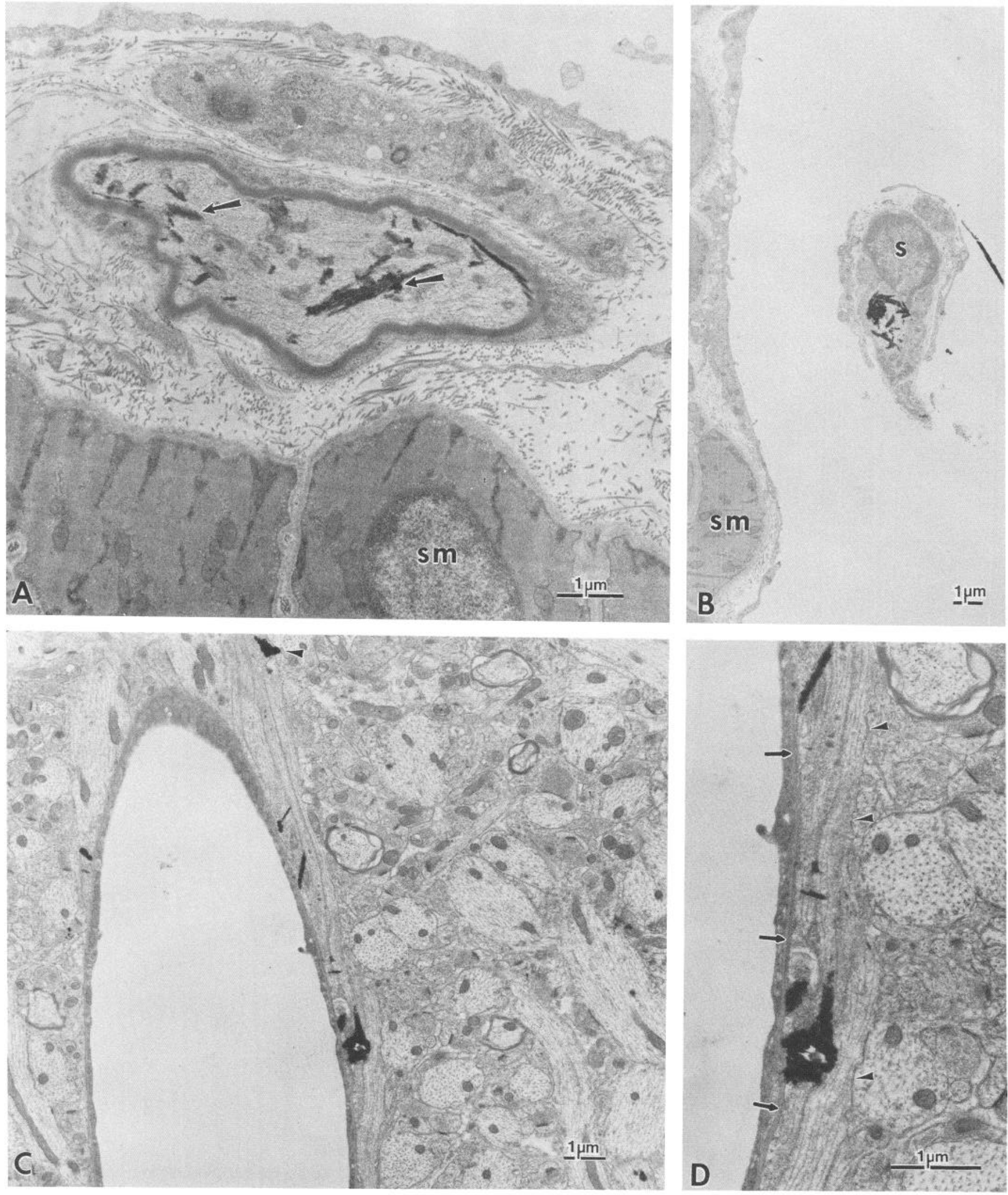

Figure 3. HRP reaction product within perivascular sympathetic fibers, $A$, Labeled myelinated fiber associated with one of the longitudinal hippocampal arteries. The reaction product (arrows) is clearly visible within the axoplasm. The smooth muscle cells ( $\mathrm{sm}$ ) of the arterial wall are visible at the bottom of the micrograph. $B$, Unmyelinated labeled fibers encased by a Schwann cell $(s)$ in the vicinity of a longitudinal hippocampal artery $(\mathrm{sm})$. A nonspecific crystal of TMB-HRP reaction product is present to the right of the Schwann cell. $C$, HRP-labeled perivascular axons associated with a blood vessel in the molecular layer. Reaction product is visible at several points along the fascicle, which appears to be leaving the blood vessel (arrowhead). D, Higher magnification of the region shown in $C$ to illustrate the absence of basal lamina between the labeled fibers and the adjacent neuropil (arrowheads). The blood vessel basal lamina is clearly visible (arrows). 

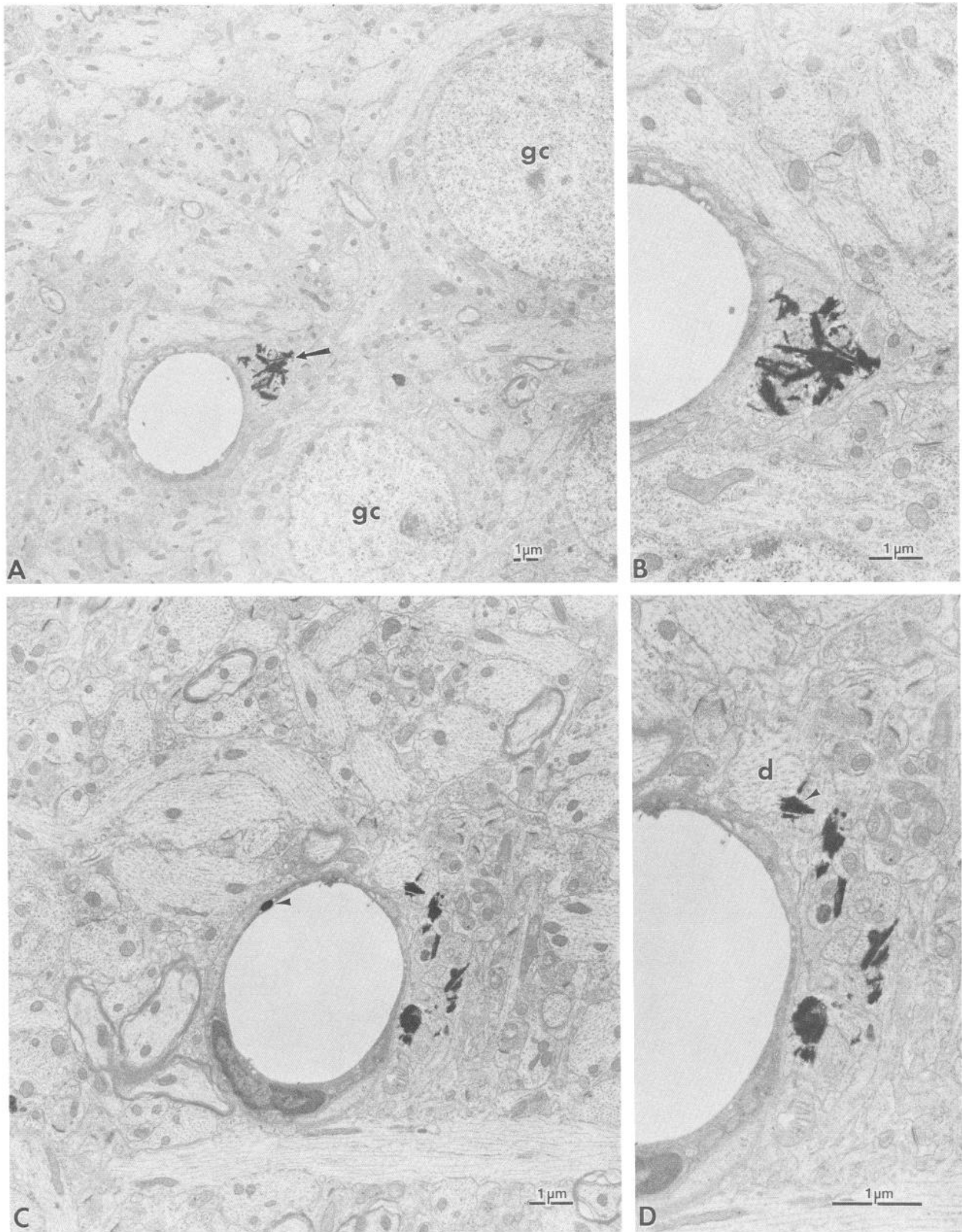

Figure 4. Examples of HRP-labeled sympathetic axons associated with capillaries within the dentate gyrus. $A$, Dense TMB reaction product (arrow) labels perivascular fibers adjacent to the granule cell layer $(\mathrm{gc})$. B. Higher magnification of the field shown in $A$ to illustrate the presence of dense-cored vesicles within the labeled profiles, although much of the ultrastructure is obscured by the reaction product. $C$, Additional example of HRP-labeled axons in which several distinct fibers can be identified. Endogenous peroxidase, occasionally observed in endothelial cells, is indicated by arrowhead. $D$, Higher magnification of the field shown in $C$. The arrowhead indicates an example of a TMB crystal that has extended beyond the fiber of origin to penetrate an adjacent dendritic profile $(d)$. 

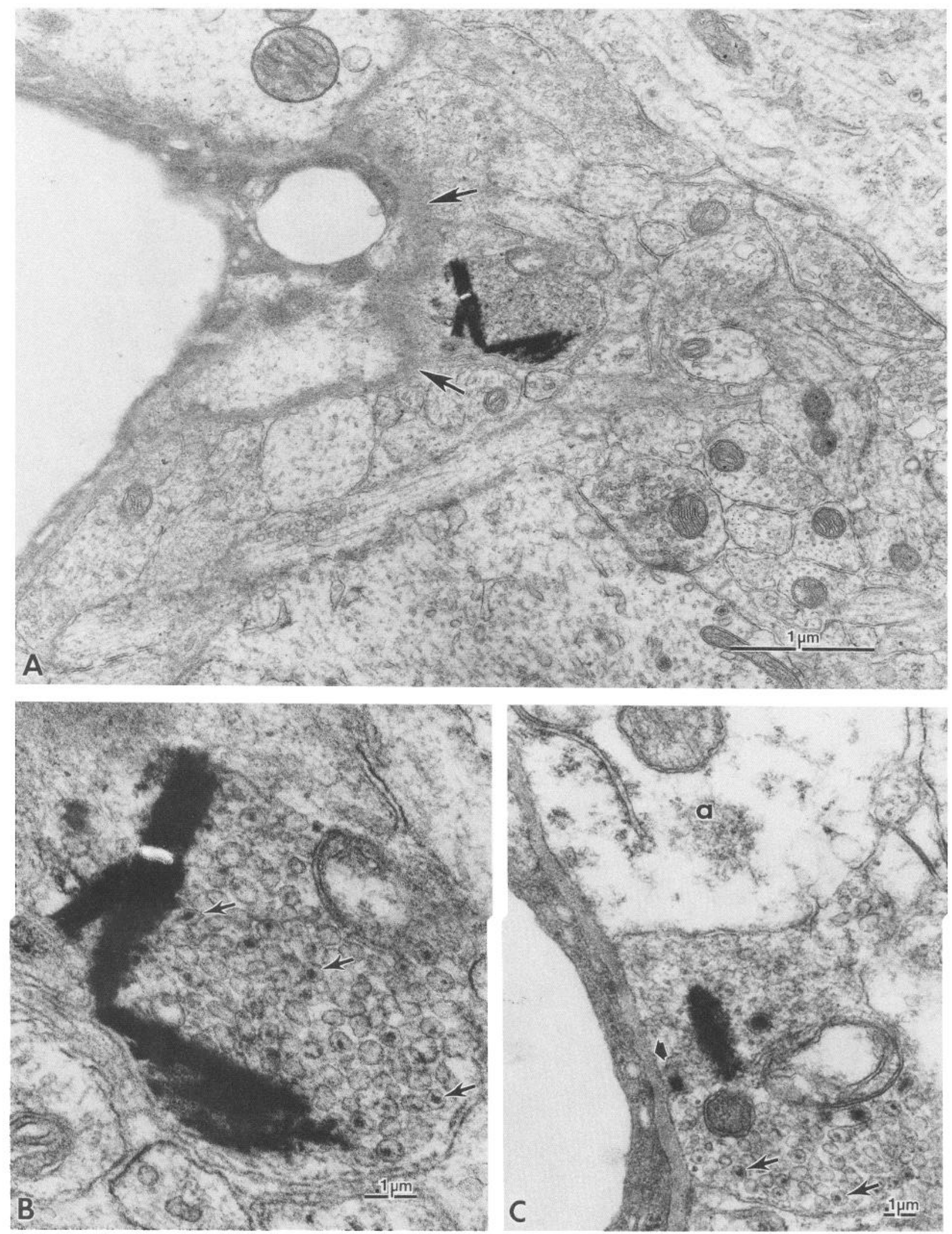

Figure 5. Examples of HRP-labeled vesicle-filled profiles associated with intraparenchymal blood vessels. $A$, Labeled vesicle-filled profile directly adjacent to the basal lamina (arrows) of the neighboring blood vessel. $B$, Higher magnification of the labeled profile shown in $A$ to illustrate the presence of numerous small dense-cored vesicles (arrows). $C$, HRP-labeled profile containing small dense-cored vesicles (long arrows). This labeled profile is directly apposed to the basal lamina (short arrow) of the adjacent blood vessel and is contacted above by an astrocytic process (a). 

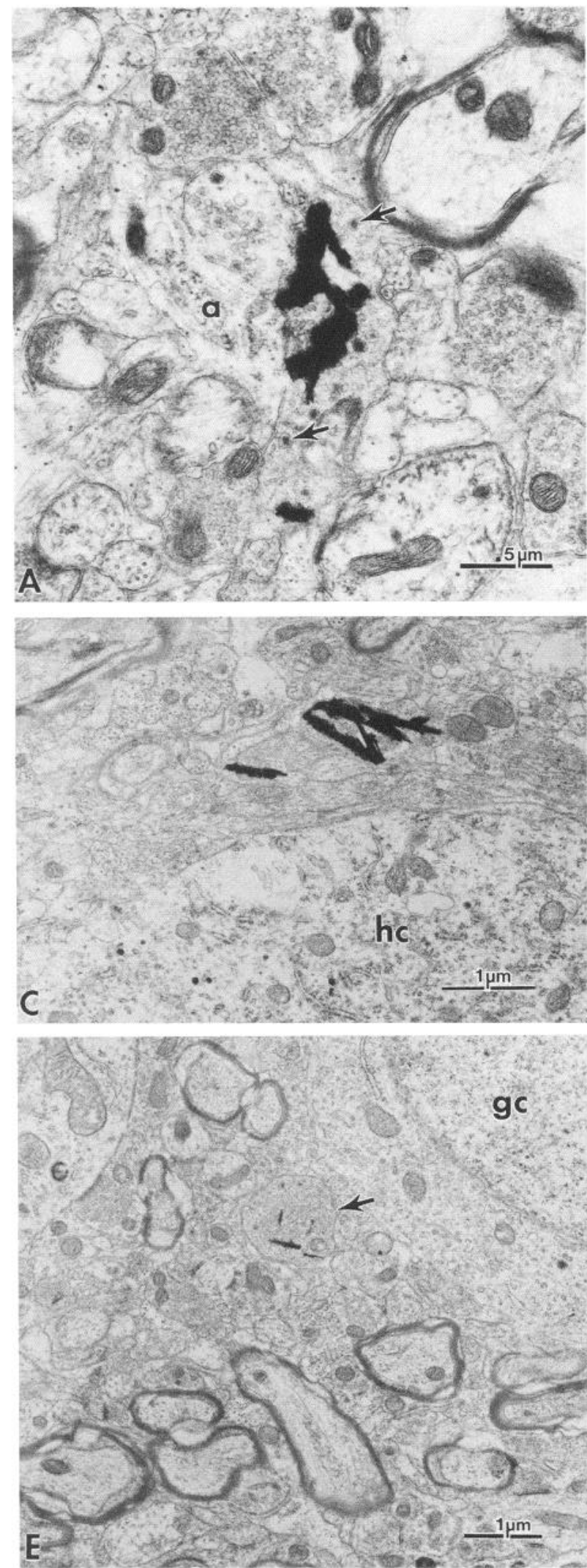
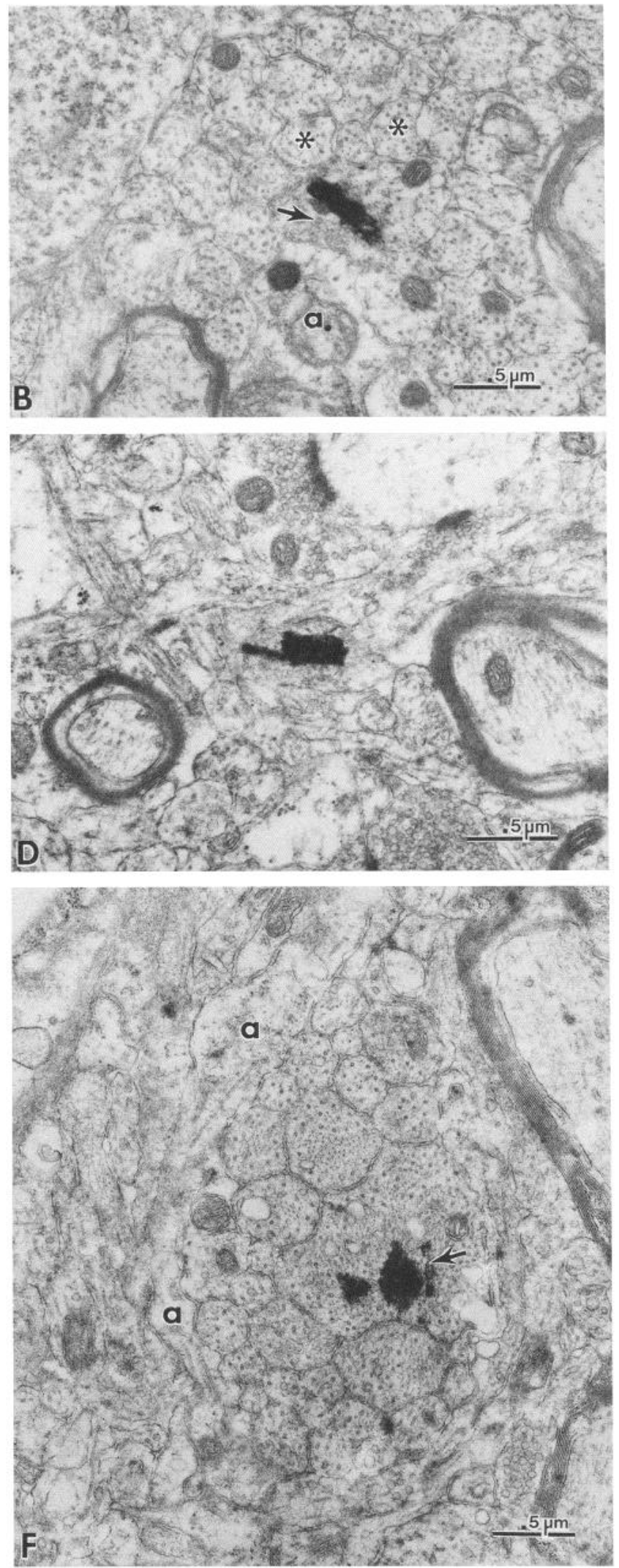

Figure 6. Examples of HRP-labeled sympathetic profiles without vascular association. $A$, Labeled profile containing several dense-cored vesicles (arrows) and contacted by an astrocytic process $(a)$. B. Labeled vesicle-filled profile (arrow) adjacent to several unmyelinated axons $(*)$ and contacted by an astrocytic process $(a)$. $C$, Two labeled profiles within the dentate hilus near a hilar cell $(h c) . D$, Labeled profile within the dentate hilus. $E$, Vesicle-filled labeled profile (arrow) within the granule cell layer. A granule cell $(g c)$ is nearby. $F$, HRP reaction product within a sympathetic axon that is part of a fascicle of unmyelinated fibers surrounded, at least in part, by astrocytic processes $(a)$. 
elements of the hippocampal neuropil (e.g., Fig. 4D). These profiles most likely represent artifactual penetration of the axonal membranes by internally expanding TMB crystals (Carson and Mesulam, 1982), and in the few instances in which we encountered this phenomenon, it in no way interfered with the successful interpretation of our data. We never saw any evidence for transneuronal transport of WGA-HRP.

One limitation of the WGA-HRP labeling procedure is that it cannot be expected to label successfully $100 \%$ of the fibers in cvery animal. Some of the variables that may affect adversely the number and staining intensity of fibers include incomplete septal lesions, less than optimal SCG injections, and, at the electron microscopic level, incubation of tissue at $\mathrm{pH} 6.0$ with resultant loss of sensitivity. There is no reason to believe, however, that the distribution, morphological features, and anatomical relationships of the fibers labeled successfully in our experiments were not representative of sympathohippocampal fibers as a whole.

\section{Sympathohippocampal sprouting}

The growth of sympathetic fibers into the rat hippocampal formation following septohippocampal denervation is a unique example of neuronal plasticity in the mature CNS. The specificity of the response, as well as a likely mechanism, have been established (Crutcher, 1987). The conclusion that this represents the establishment of a novel projection (neoinnervation) rather than expansion of a normal innervation is borne out in the present study by the complete absence of any labeled fibers within the hippocampal formation of unlesioned or controllesioned animals. As far as we are aware, there is no other example of a novel projection established in the mature mammalian brain in response to denervation. Other examples of neuronal plasticity appear to represent expansions of existent innervations (hyperinnervation). However, until now, it was not clear whether sympathetic axons actually invaded the denervated CNS neuropil or were restricted to perivascular sites. The ultrastructural relationship of the sprouted fibers to hippocampal elements has never been studied with labeling methods, although Loy and Moore (1979) referred to unpublished results in which sympathetic fibers were labeled at the electron microscopic level with 5-hydroxydopamine. They reported that in their limited sample it was not possible to determine to what extent the labeled profiles were "apposed to postsynaptic densities or are in areas adjacent to capillaries."

The association of sympathetic fibers with hippocampal blood vessels was noted in the original light microscopic studies in which fluorescence microscopy was used to visualize the sprouts (Stenevi and Bjorklund, 1978; Loy and Moore, 1979; Crutcher et al., 1981). In a subsequent light microscopic study, McGinty et al. (1982), examined the distribution of sympathohippocampal fibers in sections in which the vasculature was labeled with a fluorescent dye. They reported that sympathetic fibers in the dentate accompany penetrating blood vessels and then "leave their vascular association to collateralize within the stratum granulosum and the dentate hilus." They reported that a few fibers retained their vascular association but that these were "more the exception than the rule." We presume that the higher incidence of vascular-associated fibers in our material is a result of the greater resolution afforded by electron microscopy. Light microscopic observations are of limited value because of the inability to be certain that all vascular profiles can be satisfactorily visualized.
That sympathetic axons actually enter the CNS neuropil following septohippocampal lesions is clear from the present study. There is little doubt that in our material HRP-labeled axons are present within the hippocampal neuropil in association with a wide variety of cellular profiles. Many of the labeled sprouts appear to represent isolated axons, but we also encountered many labeled profiles that were part of axon fascicles. Some of these were very similar in appearance to the perivascular fascicles reported in previous studies (Crutcher and Chandler, 1984, 1985). If such fascicles consist entirely of sympathetic axons, as we suspect, then this further supports the suggestion that the thick fluorescent appearance of sympathetic fibers at the light microscopic level is partially due to the fasciculation of several axons into bundles that can only be resolved with the electron microscope (Crutcher and Chandler, 1984, 1985).

The presence at the electron microscopic level of small densecored vesicles in many of the labeled profiles seen in our study is consistent with the appearance of other sympathetic terminals and correlates with the histofluorescent appearance of sympathetic fibers at the light microscopic level due to their norepinephrine content. We did not observe any membrane specializations suggestive of classical synaptic contacts and cannot, as a result, draw any conclusions about synaptic (morphological) targets. Although membrane thickenings were not observed in our sample, firm conclusions on this point can only be made through extensive serial section analysis. For example, early studies suggested that central noradrenergic neurons rarely formed classical synaptic contacts, but subsequent studies using serial section analysis found that such contacts do exist. Regardless of whether sympathohippocampal axons form such synaptic contacts, if the sprouted fibers are functional and release transmitter, and there is no reason to suspect that they do not, then they could presumably affect any nearby cells that contain the appropriate membrane receptors. The question of whether sympathetic sprouts exert functional influences has been addressed in several studies, but no consensus has emerged and some results are contradictory (Kimble et al., 1980; Chafetz et al., 1982; Crutcher et al., 1983; Harrell and Davis, 1983; Barker et al., 1984; Harrell et al., 1986).

\section{Implications for understanding axonal growth}

In light of what is already known about the sympathohippocampal sprouting response, the results of the present study emphasize the unique attributes of this example of neuronal plasticity and provide hints about mechanisms of axonal growth in the mature brain. The ability of sympathetic axons, normally confined to targets outside the CNS, to sprout and invade a brain region denervated of a specific but sparse input represents an unexpected phenomenon. The actual distance traversed by the sprouting fibers is hard to determine, but the axons penetrate at least to the center of the dentate hilus (approximately $0.5-1$ $\mathrm{mm}$ from the hippocampal surface) and extend along the CA3 region to the border with $\mathrm{CA} 2$. Regenerating axons have been reported to extend similar distances in some cases (Aguayo et al., 1986; Vidal-Sanz et al., 1987), but, as mentioned above, sympathetic sprouting is not a regenerative response and occurs in a brain region that has been denervated but not directly injured. In any event, the more relevant issue may be the extent to which growing axons are found away from blood vessels (see below).

Specific features of the sprouting response reveal 2 potential controlling factors that might be involved in this example of 
nonregenerative axonal growth in the mature brain. One is the possible role that brain NGF plays in eliciting the sprouting response, and the other is the close association of the growing axons with blood vessel". Nol only is NGF, as well as its mRNA, present in substantial concentrations in the rat hippocampal formation (Crutcher and Collins, 1982; Korsching et al., 1985; Shelton and Reichardt, 1986; Whittemore et al., 1986), but there is an increase in hippocampal NGF levels following septohippocampal denervation (Collins and Crutcher, 1985; Gasser et al., 1986; Korsching et al., 1986; Whittemore et al., 1987). Furthermore, injection of NGF antiserum has been reported to block sympathetic sprouting (Springer and Loy, 1985).

Although sympathetic sprouts were observed in the hippocampal neuropil in this study, the majority of labeled profiles in our material were found closely associated with blood vessels. This perivascular disposition of the sprouts does not reflect a physical restriction of the growing fibers since in the majority of cases there is no obvious barrier, such as a duplicated basal lamina (Crutcher and Chandler, 1984), preventing their invasion of the neuropil, and, in any event, some of the fibers do leave the blood vessels. Nor does there appear to be any increase in the intrahippocampal vascular tree following medial septal lesions (Chandler and Crutcher, 1983). The affinity of the sprouted fibers for the perivascular environment is nevertheless striking and may reflect a more favorable environment for growth than that provided by the neuropil. One possible explanation for this vascular association is that the blood vessels provide a pathway of less resistance than the surrounding neuropil. Other explanations, however, should be considered. In particular, the direct apposition of labeled fibers with the vascular basal lamina may indicate the presence of a more favorable substrate for axonal growth than that provided by the neuropil. Numerous studies have demonstrated the growth-promoting activity of various extracellular matrix components (Lander et al., 1983; Manthorpe et al., 1983; Bignami et al., 1984; Carbonetto, 1984; Carbonctto ct al., 1987), which are restricted to the perivascular environment in the mature mammalian brain and spinal cord. One of these components, laminin, is a major component of basal lamina and a potent stimulator of axonal growth in vitro. Another possibility that has recently been proposed (Crutcher, 1987 ) is that there is an accumulation of a diffusible growth factor in the perivascular environment due to extracellular fluid circulation, similar to the accumulation demonstrated recently for exogenously administered protein (Rennels et al., 1985; Wakai et al., 1986).

It is also possible that a diffusible factor such as NGF could bind to extracellular matrix components in the perivascular environment to stimulate axonal growth. The importance of both diffusible and substrate-bound growth factors for extensive axonal growth in tissue culture has been established (Collins, 1978; Crutcher, 1986; Carbonetto et al., 1987), and homologous factors could provide similar advantages for axons clongating in vivo. One final possibility should also be considered. Kiernan (1979) proposed that regenerating axons require serum factors to successfully elongate. If such factors are involved in the sympathetic sprouting response and are able to breach the bloodbrain barrier, then the perivascular environment may be favored for this reason. The only weakness of this hypothesis, as applied to this example of nonregenerative growth, is that there does not appear to be any change in the blood-brain barrier, at least to proteins, in the hippocampal vasculature following septohippocampal denervation (Madison et al., 1981).
The potential role that glia play in this particular example of collateral sprouting can only be surmised. Fasciculation of axons has been suggested to reflect an influence of glia (Noble et al., 1984), and the bundling of sympathetic axons may reflect a similar role for central glia in this response. Many of our labeled sympathetic fibers, including the fascicles, are closely associated with presumed astrocytic processes. Astrocytes in the mature brain have long been suspected of inhibiting axonal growth. Liuzzi and Lasek (1987) recently reported that astrocytes may inhibit regeneration by activating a "physiological stop pathway." Since the sympathetic sprouts in this study are growing in the presence of mature astrocytes, a similar inhibition does not appear to be involved in this example of axonal clongation.

On the other hand, previous studies have suggested that astrocytes produce trophic factors in tissue culture (Lindsay, 1979; Banker, 1980; Liesi et al., 1981; Furukawa et al., 1986) and may play an active role in the guidance of axons during development and/or regeneration (Singer et al., 1979; Smith et al., 1986). In the mature nervous system, however, peripheral glial elements clearly provide a more favorable substrate for axonal growth in vitro (Schwab and Thoenen, 1985; Carbonetto et al., 1987) and are thought to account for the successful axonal elongation in the peripheral nerve grafting experiments of Aguayo and coworkers (1985).

The ability of sympathetic axons to invade the CNS indicates that favorable conditions for nonregenerative axonal growth within the CNS can occur in the mature brain. What is not apparent is whether such growth is desirable. This particular sprouting response presumably reflects a fortuitous situation created by selective damage to septohippocampal neurons. It is unlikely that it represents an adaptive response to brain injury (Crutcher, 1987). Nevertheless, the presence of sympathetic fibers within the CNS could influence neuronal function and might occur in the human brain where there is loss of basal forebrain cholinergic neurons, e.g., Alzheimer's disease. If so, and such sprouting somehow contributes to functional recovery of the denervated tissue, measures to accelerate or enhance such growth should be developed. On the other hand, if such sprouting is maladaptive and interferes with recovery, then discouraging such growth would be desirable. In any event, additional studies are needed to uncover the variables that may influence axonal growth in the mature mammalian CNS.

\section{References}

Aguayo, A. J. (1985) Axonal regeneration from injured neurons in the adult mammalian central nervous system. In Synaptic Plasticity, C. W. Cotman, ed., pp. 457-484, Guilford, New York.

Aguayo, A. J., S. David, P. Richardson, and G. M. Bray (1982) Axonal elongation in peripheral and central nervous system transplants. Adv. Cell Neurobiol. 3: 215-234.

Aguayo, A. J., et al. (1986) In Retinal Systems, Regenerations and Transplants, E. Agardh and B. Ehringer, eds., pp. 257-270, Elsevier, Amsterdam.

Banker, G. A. (1980) Trophic interactions between astroglial cells and hippocampal neurons in culture. Science 209: 809-810.

Barker, D. J., A. J. Howard, and F. H. Gage (1984) Functional significance of sympathohippocampal sprouting: Changes in single cell spontaneous activity. Brain Res. 291: 357-363.

Benfey, M., and A. J. Aguayo (1982) Extensive elongation of axons from rat brain into peripheral nerve grafts. Nature 296: 150-152.

Bernstein, J. J., and M. E. Bernstein (1971) Axonal regeneration and formation of synapses proximal to the sitc of lesion following hemisection of the rat spinal cord. Exp. Neurol. 30: 336-351.

Bignami, A., N. H. Chi, and D. Dahl (1984) Regenerating dorsal roots and the nerve entry zone: An immunofluorescence study with neurofilament and laminin antisera. Exp. Neurol. 85: 426-436. 
Bjorklund, A., and U. Stenevi (1972) Nerve growth factor: Stimulation of regenerative growth of central noradrenergic neurons. Science 175: 1251-1253.

Bjorklund, A., and U. Stenevi (1979) Regeneration of monoaminergic and cholinergic neurons in the mammalian central nervous system. Physiol. Rev. 59: 62-100.

Bjorklund, A., and U. Stenevi (1984) Intracerebral neural implants: Neuronal replacement and reconstruction of damaged circuitries. Annu. Rev. Neurosci. 7: 279-308.

Carbonetto, S. (1984) The extracellular matrix of the nervous system. Trends Neurosci. 7: 382-387.

Carbonetto, S., D. Evans, and P. Cochard (1987) Nerve fiber growth in culture on tissue substrata from central and peripheral nervous systems. J. Neurosci. 7: 610-620.

Carson, K. A., and M.-M. Mesulam (1982) Electron microscopic demonstration of neural connections using horseradish peroxidase: A comparison of the tetramethylbenzidine procedure with seven other histochemical methods. J. Histochem. Cytochem. 30: 425-435.

Chafetz, M. D., S. Evans, and F. H. Gage (1982) Recovery of function from septal damage and the growth of sympathohippocampal fibers. Physiol. Psychol. 10: 391-398.

Chandler, J. P., and K. A. Crutcher (1983) Medial septal lesions do not result in increased vascularization of the dentate gyrus in the rat. Soc. Neurosic. Abstr. 9: 986.

Clark, W. E. Le G. (1942) The problem of neuronal regeneration in the central nervous system. I. The influence of spinal ganglia and nerve fragments grafted in the brain. J. Anat. 77: 20-48.

Clark, W. E. Le G. (1943) The problem of neuronal regeneration in the central nervous system. II. The insertion of peripheral nerve stumps into the brain. J. Anat. 77:251-259.

Collins, F. (1978) Induction of neurite outgrowth by a conditioned medium factor bound to culture substratum. Proc. Natl. Acad. Sci. USA 75: 5210-5213.

Collins, F., and K. A. Crutcher (1985) Neurotrophic activity in the adult rat hippocampal formation: Regional distribution and increase after septal lesion. J. Neurosci. 5: 2809-2814.

Cotman, C. W., and M. Nieto-Sampedro (1981) Synapse replacement in the nervous system of adult vertebrates. Physiol. Rev. 61: 684784.

Cotman, C. W., D. A. Matthews, D. Taylor, and G. Lynch (1973) Synaptic rearrangement in the dentate gyrus: Histochemical evidence of adjustments after lesions in immature and adult rats. Proc. Natl. Acad. Sci. USA 70: 3473-3477.

Crutcher, K. A. (1982) Histochemical studies of sympathetic sprouting: Fluorescence morphology of noradrenergic axons. Brain Res. Bull. 9: 501-508.

Crutcher, K. A. (1986) The role of growth factors in neuronal development and plasticity. Crit. Rev. Clin. Neurobiol. 2: 297-333.

Crutcher, K. A. (1987) Sympathetic sprouting in the central nervous system: A model for studies of axonal growth in the mature mammalian brain. Brain Res. Rev. 12: 203-233.

Crutcher, K. A., and J. P. Chandler (1984) Association of basal lamina with peripheral axons elongating within the rat central nervous system. Brain Res. 308: 177-181

Crutcher, K. A., and J. P. Chandler (1985) Evidence for sprouting specificity following medial septal lesions in the rat. J. Comp. Neurol. 237: 116-126.

Crutcher, K. A., and F. Collins (1982) In vitro evidence for two distinct hippocampal growth factors: Basis of neuronal plasticity? Science 217: 67-68.

Crutcher, K. A., L. Brothers, and J. N. Davis (1981) Sympathetic noradrenergic sprouting in response to central cholinergic denervation: A histochemical study of neuronal sprouting in the rat hippocampal formation. Brain Res. 210: 115-128.

Crutcher, K. A., R. P. Kesner, and J. M. Novak (1983) Medial septal lesions, radial arm maze performance, and sympathetic sprouting: $\mathbf{A}$ study of recovery of function. Brain Res. 262: 91-98.

David, S., and A. J. Aguayo (1981) Axonal elongation into peripheral nervous system "bridges" after central nervous system injury. Science 214: 931-933.

de la Torre, J. C. (1980) An improved approach to histofluorescence using the SPG method for tissue monomines. J. Neurosci. Methods 3: $1-5$.

Emson, P. C., A. Bjorklund, and U. Stenevi (1977) Evaluation of the regenerative capacity of central dopaminergic, noradrenergic and cho- linergic neurons using iris implants as targets. Brain Res. 135: 87105.

Fujii, M., and T. Kusama (1984) Fixation of horseradish peroxidase reaction products with ammonium molybdate. Neurosci. Res. 1: 153156.

Furukawa, S., Y. Furukawa, E. Satoyoshi, and K. Hayashi (1986) Synthesis and secretion of nerve growth factor by mouse astroglial cells in culture. Biochem. Biophys. Res. Commun. 136: 57-63.

Gage, F. H., A. Bjorklund, and U. Stenevi (1984) Cells of origin of the ventral cholinergic septohippocampal pathway undergoing compensatory collateral sprouting following fimbria-fornix transection. Neurosci. Lett. 44: 211-216.

Gasser, U. E., G. Weskamp, U. Otten, and A. R. Dravid (1986) Time course of the elevation of nerve growth factor (NGF) content in the hippocampus and septum following lesions of the septohippocampal pathway in rats. Brain Res. 376: 351-356.

Guth, L. (1974) Axonal regeneration and functional plasticity in the central nervous system. Exp. Neurol. 45: 606-654.

Harrell, L. E., and J. N. Davis (1983) Sympathetic sprouting and recovery of a spatial behavior. Exp. Neurol. 82: 379-390.

Harrell, L. E., J. H. Haring, and J. N. Davis (1986) Peripheral sympathetic ingrowth can alter metabolic activity within the hippocampal formation. Exp. Neurol. 91: 622-627.

Kiernan, J. A. (1979) Hypotheses concerned with axonal regeneration in the mammalian nervous system. Biol. Rev. 54: 155-197.

Kimble, D. P., R. Bremiller, and G. Stickrod (1980) Failure to find a behavioral role for anomalous sympathetic innervation of the hippocampus in male rats. Physiol. Behav. 25: 675-681.

Korsching, S., G. Auburger, R. Heumann, J. Scott, and H. Thoenen (1985) Levels of nerve growth factor and its mRNA in the central nervous system of the rat correlate with cholinergic innervation. EMBO J. 4: 1389-1393.

Korsching, S., R. Heumann, H. Thoenen, and F. Hefti (1986) Cholinergic denervation of the rat hippocampus by fimbrial transection leads to a transient accumulation of nerve growth factor (NGF) without change in mRNA ${ }^{\mathrm{NGF}}$ content. Neurosci. Lett. 66: 175-180.

Kromer, L. F., A. Bjorklund, and U. Stenevi (1981) Regeneration of the septohippocampal pathways in adult rats is promoted by utilizing embryonic hippocampal implants as bridges. Brain Res. 210: 173200.

Lander, A. D., K. Tomaselli, A. L. Calof, and L. F. Reichardt (1983) Studies on extracellular matrix components that promote neurite outgrowth. Cold Spring Harbor Symp. Quant. Biol. 48: 611-623.

Liesi, P., D. Dahl, and A. Vaheri (1981) Laminin is produced by early rat astrocytes in primary culture. J. Cell Biol. 96: 920-924.

Lindsay, R. M. (1979) Adult rat brain astrocytes support survival of both NGF-dependent and NGF-insensitive neurons. Nature 282: 8082.

Liu, C. N., and W. W. Chambers (1958) Intraspinal sprouting of dorsal root axons. Arch. Neurol. Psychiatry 79: 46-61.

Liuzzi, F. J., and R. J. Lasek (1987) Astrocytes block axonal regeneration in mammals by activating the physiological stop pathway. Science 237: 642-645.

Lorente de No, R. (1921) La generacion de la medula espinal en las larvas de batracio. Trab. Lab. Invest. Biol. Universidad Madrid 19. 147-183.

Loy, R., and R. Y. Moore (1979) Regenerative growth of sympathetic fibers into rat hippocampus. In Catecholamines: Basic and Clinical Frontiers, E. Usdin, E. J. Kopin, and J. Barchas, eds., pp. 1336-1338, Pergamon, New York.

Loy, R., T. A. Milner, and R. Y. Moore (1980) Sprouting of sympathetic axons in the hippocampal formation: Conditions necessary to elicit ingrowth. Exp. Neurol. 67: 399-411.

Madison, R., K. A. Crutcher, and J. N. Davis (1981) Sympathohippocampal neurons are inside the blood-brain barricr. Brain Res. 213: 183-189.

Manthorpe, E., E. Engrall, F. Rudslahti, F. M. Longo, G. E. Davis, and S. Varon (1983) Laminin promotes neuritic regeneration from cultured peripheral and central neurons. J. Cell Biol. 97: 1882-1890.

Marfurt, C. F., E. M. Zaleski, C. E. Adams, and C. L. Welther (1986) Sympathetic nerve fibers in rat orofacial and cerebral tissues as revealed by the HRP-WGA tracing technique: A light and electron microscopic study. Brain Res. 366: 373-378.

McGinty, J. F., T. A. Milner, and R. Loy (1982) Association of sympathetic axons in denervated hippocampus to intracerebral vascula- 
ture. I. Fluorescence histochemistry combining glyoxylic acid and pontamine sky blue. Anat. Embryol. 164: 95-100.

Mesulam, M.-M. (1978) Tetramethylbenzidine for horseradish peroxidase neurohistochemistry: A non-carcinogenic blue reaction product with superior sensitivity for visualizing neural afferents and efferents. J. Histochem. Cytochem. 26: 106-117.

Nobin, A., H. G. Baumgarten, A. Bjorklund, L. Lachenmayer, and U. Stenevi (1973) Axonal degeneration and regeneration of the bulbospinal indolamine neurons after 5,6-dihydroxytryptamine treatment. Brain Res. 56: 1-24.

Noble, M., J. Fok-Seang, and J. Cohen (1984) Glia are a unique substrate for the in vitro growth of central nervous system neurons. J. Neurosci. 4: 1892-1903.

Nygren, L.-G., L. Olson, and A. Seiger (1971) Regeneration of monoamine-containing axons in the developing and adult spinal cord of the rat following intraspinal 6-OH-dopamine injections or transections. Histochemie $28: 1-15$.

Nygren, L.-G., K. Fuxe, G. Jansson, and L. Olson (1974) Functional regeneration of 5-hydroxytryptamine nerve terminals in the rat spinal cord following 5,6-dihydroxytryptamine induced degeneration. Brain Res. 78: 377-394.

Raisman, G. (1969) Neuronal plasticity in the septal nuclei of the adult rat. Brain Res. 14: 25-48.

Raisman, G., and P. M. Field (1973) A quantitative investigation of the development of collateral reinnervation after partial deafferentation of the septal nuclei. Brain Res. 50: 241-264.

Ramon y Cajal, S. (1928) Degeneration and Regeneration of the Nervous System, R. M. May, trans., Oxford U. P., New York.

Rennels, M. L., T. F. Gregory, O. R. Blaumanis, K. Fujimoto, and P. A. Grady (1985) Evidence for a "paravascular" fluid circulation in the mammalian central nervous system, provided by the rapid distribution of tracer protein throughout the brain from subarachnoid space. Brain Res. 326: 47-63.

Richardson, P. M., U. M. McGuinness, and A. J. Aguayo (1980) Axons from CNS neurons regenerate into PNS grafts. Nature 284: 264-265.

Sakumoto, C., K. Bielenberg, and B. Spatz (1980) Electron microscopic visualization of tetramethylbenzidine reaction production horseradish peroxidase neurohistochemistry. Cell Mol. Biol. 26: 211 216.

Schneider, G. E. (1973) Early lesions of the superior colliculus: Factors affecting the formation of abnormal retinal projections. Brain Behav. Evol. 8: 73-109.

Schonitzer, K., and H. Hollander (1981) Anterograde tracing of horseradish peroxidase (HRP) with the electron microscope using the tetramethylbenzidine reaction. J. Neurosci. Methods 4: 373-383.

Schwab, M., and H. Thoenen (1985) Dissociated neurons regenerate into sciatic but not optic nerve explants in culture irrespective of neurotrophic factors. J. Neurosci. 5: 2415-2423.
Shelton, D. L., and L. F. Reichardt (1986) Studies on the expression of the beta nerve growth factor (NGF) gene in the central nervous system: Level and regional distribution of NGF mRNA suggest that NGF functions as a trophic factor for several distinct populations of neurons. Proc. Natl. Acad. Sci. USA 83: 2714-2718.

Singer, M. R., R. H. Norlander, and M. Egar (1979) Axonal guidance during embryogenesis and regeneration in the spinal cord of the newt: The blueprint hypothesis of neuronal pathway patterning. J. Comp. Neurol. 185: 1-22.

Smith, G. M., R. H. Miller, and J. Silver (1986) Changing role of forebrain astrocytes during development, regenerative failure, and induced regeneration upon transplantation. J. Comp. Neurol. 251: $23-43$.

Springer, J. E., and R. Loy (1985) Intrahippocampal injections of antiserum to nerve growth factor inhibit sympathohippocampal sprouting. Brain Res. Bull. 15: 629-634.

Stenevi, U., and A. Bjorklund (1978) Growth of vascular sympathetic axons into the hippocampus after lesions of the septo-hippocampal pathway: A pitfall in brain lesion studies. Neurosci. Lett. 7: 219-224.

Sturmer, C., K. Bielenberg, and B.Spatz (1981) Electron microscopical identification of 3,3',5,5'-tetramethylbenzidine reacted horseradish peroxidase after retrograde axoplasmic transport. Neurosci. Lett. 23: $1-6$.

Tello, F. (1911) La influencia del neurotropismo en la regeneracion de los centros nerviosos. Trab. Lab. Invest. Biol. Universidad Madrid 9: $123-159$

Vidal-Sanz, M., G. M. Bray, M. P. Villegas-Pérez, S. Thanos, and A. J. Aguayo (1987) Axonal regeneration and synapse formation in the superior colliculus by retinal ganglion cells in the adult rat. J. Neurosci. 7: 2894-2909.

Wakai, S., S. E. Meiselman, and M. W. Brightman (1986) Focal circumvention of blood-brain barrier with grafts of muscle, skin and autonomic ganglia. Brain Res. 386: 209-222.

Westman, J., N. Danckwardt-Lilliestrom, E. Dietrichs, B. A. Svensson, and F. Walberg (1986) Ultrastructure of spinal efferents to the lateral reticular nucleus: An EM study using anterograde transport of WGAHRP complex. J. Comp. Neurol. 246: 301-311.

Whittemore, S. R., T. Ebendal, I. I arkfors, I. Olson, A. Seiger, I. Stromberg, and H. Persson (1986) Development and regional expression of beta nerve growth factor messenger RNA and protein in the rat central nervous system. Proc. Natl. $\Lambda$ cad. Sci. USA 83: $817-821$

Whittemore, S. R., L. Larkfors, T. Ebendal, V. R. Holets, A. Ericsson, and $H$. Persson (1987) Increased beta-nerve growth factor messenger RNA and protein levels in neonatal rat hippocampus following specific cholinergic lesions. J. Neurosci. 7: 244-251.

Windle, W. F. (1956) Regeneration of axons in the vertebrate central nervous system. Physiol. Rev. 36: 426-440. 